\title{
FETO MORTO: ATUAÇÃO DA ENFERMEIRA FRENTE AO SENTIMENTO MATERNO*
}

\author{
Anna Maria Hecker Luz** \\ Emília da Silva Santos*** \\ Sandra Maria de Abreu Mendes**** \\ Sônia Maria Motink Agostini**
}

\begin{abstract}
RESUMO - As mães de natimortos, de gravidez desejada ou não, são criaturas que desde a constatação daquela morte, permanecem, por um perlodo de aproximadamente um mês, profundamente contristadas, deprimidas, com sentimento de solidão e questionando acerca da vida. Nestas condições, torna-se importante um adequado acompanhamento destas pacientes; ao princípio, pela equipe dos centros obstétricos; subseqüentemente, pela equipe de atendimento das unidades de internação obstétrica; finalmente, pelos próprios familiares das paciente, já no âmbito domiciliar. A preparação de todas estas pessoas, que de alguma forma participam desta assistência, é objeto de discussão neste artigo, visando ao delineamento dum modelo de assistência de enfermagem para essas mães.
\end{abstract}

ABSTRACT - Mothers of stillborns, with wanted or not pregnancy, are creatures who remain, since the evidence of that death, for a period of approximately a month, in a state of profound grievousness and depression, carrying a feeling of solitude and of questioning about life. On that circunstances, an adequate attendance of such patients becomes important: at the beginning, by the proper persons of obstetric centers; subsequently, by those who are responsible for the attendance at the units of obstetric internation; finally, by the patient's familiars themselves, already at the domiciliary ambit. The preparation of all these persons, who in same way participate in this assistance, is the subject of discussion in this article, which aims at a delineation of a nursing model of assistance for these mothers.

\section{INTRODUÇÃO}

"Os pais de feto morto aprendem através de nósos profissionais da área obstétrica - que a morte não é para ser mencionada".

O'DONOHUE

Foi desde as primeiras experiências vivenciadas no tratar com as mães de feto morto que as autoras sentiram-se despertadas para o leque de questões emocionais associadas aquele fato: não se trata aqui de uma morte em si, mais do que isso, trata-se da frustração de toda uma expectativa vital que a mulher traz consigo ao longo da gestação. Esta dimensão humana é inescapável e os profissionais da equipe de atendimento, a princípio, sentem-se inseguros no que diz respeito ao "como assistir a paciente".

Se por um lado, com os avanços dos métodos propedêuticos, o diagnóstico do óbito fetal, hoje em dia, é tão precoce como preciso, por outro lado perdura, naturalmente, a sobrecarga emocional que se segue a sua comprovação.

Preparados para o evento da vida e para sua preservação sob as condições mais saudáveis possíveis, os profissionais da área de saúde quando presenciam a morte inelutável, sentem-se despreparados, constran- gidos, contristados. Com tanto mais razão frente à morte fetal: uma expectativa de nova vida que se vê consumida.

Assim, as autoras realizam aqui um estudo das questões que exsurgem a cada natimortalidade, procurando, também, discutir formas adequadas de auxílio à mãe nestas horas de aflição.

Compete, ao princípio, uma breve revisão bibliográfica com vistas à obtenção de alguns elementos acerca do problema.

Nas palavras de DUARTE et alii (1985), a morte fetal é uma complicação relativamente freqüente, trazendo em seu contexto dificuldades não somente obstétricas, como também, distúrbios clínicos e psicológicos. Embora quase a totalidade das gravidez tenham um desfecho favorável, esta vulnerabilidade raramente é desafiada. (1982):

Cabe notar a afirmação de MALDONADO

"Por mais que se pense na possibilidade de ocorrer a morte fetal, quando esta ocorre provoca violenta quebra de expectativa, instalando-se uma situação crítica para a família e equipe que a assiste".

* Trabalho classi ficado em $1^{\circ}$ lugar-Prêmio EDTH MAGALHÃES FRANKEL - 40 CBEn-Belém.

** Mestre em Enfermagem Materno-Infantil.

Professora Adjunta do Departamento de Enfermagem Materno-Infantil da Escola de Enfermagem da UFRGS.

*** Mestre em Enfermagem na Saúde do Adulto.

Professora Assistente do Departamento de Enfermagem Materno-Infantil da Escola de Enfermagem da UFRGS.

**** Especialista em Enfermagem Obstétrica.

Professora Titular do Departamento de EnfermagemMaterno-Infantil da Escola de Enfermagemda UFRGS.

Coordenadora do Grupo de Enfermagem do Hospital de Clínicas de Porto Alegre - HCPA. 
Considera, ainda, esta autora que a gravidez envolve a dialética vida-morte. Perdas tanto intra como extra-uterina precoces evidenciam a noção de fragilidade da vida.

Para HALSTEAD (1974), a atuação do profissional que assiste esta paciente em crise deverá pautarse pela compreensão da expressão dos seus sentimentos e tratar de discernir algum dos temores ambivalentes que obscureçam a questão.

Embora MONTENEGRO et alii (1981) considere que uma vez constatada a morte fetal a interrupção da gravidez seja o principal problema a ser resolvido, acredita-se que as alterações emocionais que se instalam na mãe, requerem, por parte da equipe de saúde, uma atenção tão especial quanto a dada ao aspecto físico.

A importância de ajudar a paciente a enfrentar a crise, of erecendo-lhe oportunidades para falar sobre sua dor e suas aflições, é salientada por CADDEN (1980).

A partir dessas constatações, sentiram as autoras a necessidade inicial de realizar um estudo que permitisse elaborar um modelo de assistência de enfermagem para as mães de feto morto. Entretanto, na medida em que se dava início à implementação do projeto, foram sendo analisados novos elementos que, aos poucos, permitiam fazer divisar o nível de complexidade do tema e conseqüentemente, a dificuldade da realização desta proposta. Neste sentido, algumas questões vieram à tona e orientaram para os objetivos deste trabalho. A saber:

- Qual a freqüência do evento natimortalidade?

- Quais as principais características emocionaiscomportamentais das mães de feto morto?

- que tipo de informação é dada às mães acerca da morte fetal?

- Que sentimentos estas mães expressam com relação à morte do filho?

- Que suporte de apoio estas mães recebem?

As respostas a estas questões-críticas serviriam, então, de ponto de partida para buscar o primeiro contato com a realidade.

\section{METODOLOGIA}

A presente proposta tem natureza essenciamente qualitativa, constituindo-se em estudo de caso, onde comparece como técnica de trabalho a entrevista semi estruturada.

Local de Estudo - Entre os hospitais de Porto Alegre com serviço de maternidade, foram selecionados três, em função do número mensal de partos e de sua localização dentro do perímetro urbano.

Nestes hospitais, o trabalho foi desenvolvido junto à Unidade de Internação Obstétrica (UIO). Esta unidade constitui-se no ambiente ideal, não só para o levantamento dos sentimentos expressos pelas pacientes e seus familiares, como para a análise da assistência prestada pela equipe, tendo em vista que a morte já ocorreu. Além do mais, a UIO oferece condições para a concretização da entrevista individualizada.

População e Amostra - Foi constituída pela totalidade das mães de feto morto (FM) dos hospitais em estudo.

Esta população constou de 168 mães (duas entre elas com parto gemelar de FM). Realizou-se entrevistas com 111 delas, perfazendo um total de $65 \%$ da população. $O$ universo não foi totalmente atingido pela ocorrência de alta hospitalar antes da entrevista.

As entrevistas foram realizadas - no período de 01 de setembro de 1986 a 31 de agosto de 1987 - com todas as informantes enquadradas nos critérios de morte fetal e em que a expulsão ou extração do concepto tenha ocorrido após o momento da admissão hospitalar.

Coleta de Dados - A técnica empregada para a coleta de dados foi a de entrevista semi-estruturada com pacientes obstétricas com 18 a 36 horas de puerpério.

As entrevistas foram realizadas pelas autoras, após a consulta ao prontuário para a obtenção de dados pessoais, obstétricos e dos relacionados com a morte fetal.

Considerou-se o procedimento acima citado, como uma fase preliminar para as que vềm a seguir discriminadas.

Primeira Fase: Exploratória - As questões críticas iniciais, emergentes das experiências de desconforto sentidas pelo grupo, foram sendo reformuladas à medida em que se desenvolvia a pesquisa de campo. Esta fase, além do que, caracterizou-se pela ambientação e adaptação das autoras frente às situações vivenciadas pelas mães de feto morto.

Segunda Fase: Delimitação do Estudo - Uma vez alcançado o domínio da situação (lidar com os sentimentos expressos pelas mães de feto morto) e identificadas as questões consideradas básicas, as autoras julgam ter passado a desenvolver com naturalidade e objetividade as entrevistas. Nestas condições, sentiu-se a necessidade de um aprofundamento dos casos e, para tanto, passou-se a executar um acompanhamento posterior: através, de entrevistas domiciliares com 19 mães no terceiro mês de puerpério, pois segundo POWELL (1986), neste período já deveria ter-se iniciado o processo de luto.

Os registros foram realizados logo após as entrevistas para preservar as informações obtidas de quaisquer inferências.

No decorrer do trabalho, utilizou-se termos específicos, conceituados a seguir.

Perda Fetal - "Perda feta é a morte do produto da concepção antes da expulsão ou extração completa do corpo da mãe, independente da duração da gestação" (OMS, 1952). Apesar deste conceito não levar em conta a duração da gestação, a classificação utilizada para as perdas fetais é de "precoce até 19 semanas, intermediárias de 20 a 27 semanas e tardia de 28 ou mais semanas" (L AURENTI, 1987).

Feto Morto - "Produto da concepção que ao nascer não apresenta qualquer sinal de vitalidade" (OMS apud VITIEL LO).

Acatando recomendações da OMS (1975) que se determine a classificação da perda fetal para a correta comparação com outros-autores, destaca-se que foram incluídos no estudo, apenas os natimortos com peso igual ou superior a $500 \mathrm{~g}$, com 20 semanas ou mais de gestação (perdas intermediárias e tardias). Nestas con dições, o feto já apresenta caracteristicas de aparência humana e não pode ser incinerado. Assim, há necessidade da emissão de atestado de óbito e, conseqüentemente, Registro Civil para sepultamento (L AUREN- 
TI, 1987). Estes procedimentos, oficializam a perda fetal e a vivência do processo da perda e luto por parte da parturiente e sua família.

\section{RESULTADOS}

\section{Caracterização da Amostra}

Os resultados aqui descritos são produto de um estudo realizado com mães de feto morto em unidades de internação obstétrica e que não teve por objetivo estabelecer generalizações: a proposta é a de exprimir e ilustrar a experiência vivenciada pelas mesmas em relação à morte do filho. É, portanto, um estudo qualitativo em que os dados percentuais e quantitativos têm mais finalidade ilustrativa do que conclusiva em relação às mães de feto morto de modo geral.

O grupo em estudo é constituído, em sua maioria, por mulheres na faixa etária de 25 a 34 anos de idade, que viviam com o pai da criança, estando em primeira ou segunda gestação e parturição. Fazem parte, entretanto, de uma minoria dentre as puérperas assistidas nas maternidades. durante os doze meses de estudo (1986/1987) houve 8.234 nascimentos nas maternidades em estudo. Destes, 170 foram de natimortos o que representa um coeficiente de natimortalidade de $20,6 \%$.

No Brasil, em 1980, a taxa de natimortalidade foi de 26,6 por mil nascidos vivos, sendo que, especificamente, na Região Sul 19,7 por mil (VITIEL LO, 1984).

A importância do estudo da natimortalidade vai muito além da interpretação de definições e fórmulas, de análises de índices nacionaịs ou regionais e até mesmo de maternidades: torna-se importante a averiguação das razões destas ocorrências.

Para FIORI et alii (1986), a mortalidade fetal "expressa não somente a qualidade da assistência prestada pela maternidade mais, sobretudo, a saúde da população de gestantes admitidas e a qualidade da assistência pré-natal recebida".

Sendo que, quanto a esta última, verificou-se que, das 111 mães entrevistadas, $17(15,3 \%)$ não tiveram qualquer tipo de assistência pré-natal na gestação. Este percentual aumenta ainda se considerados os 34 casos $(31,2 \%)$ daquelas que não atingiram o número mínimo preconizado pela OMS (1952) que é de seis consultas pré-natais na gestação. Portanto, $51(45,9 \%)$ delas não realizaram pré-natal satisfatório que atendesse aos aspectos preventivos e educacionais pretendidos, colocando estas gestações no grupo de risco.

Este fato é confirmado pelo estudo realizado em São Paulo por L IPPI et alii (1986) numa casuística de 9.348 eventos obstétricos com a ocorrência de 220 perdas fetais. Neste caso, houve associação significativa entre o aumento de mortalidade e o número reduzido (de quatro a zero) de consultas durante a gestação.

Dentro os tipos de partos, o vaginal foi mais freqüente com percentual de aproximadamente $77 \%$ (83 casos), embora houvesse um significativo número de cesáreas (24 casos) não esperados, desde que, estando o feto morto, haveria preferência pelo parto vaginal.

Ao se analisar as indicações do parto cirúrgico, verificou-se que as razões são basicamente por indicações maternas, uma vez que somente em quatro $(16,6 \%)$ se deu em relação ao feto, tendo esta inter- venção operatória ocorrido no grupo das gestantes de mais de 28 semanas de gestação.

No presente estudo a ocorrência de natimortalidade foi verificada, em sua maioria, com mais de 28 semanas gestacionais.

Deste grupo, 72 mães apresentaram intercorrências durante a gestação, sendo a hipertensão arterial a que apareceu em maior número (31 casos).

No que concerne à hipótese diagnóstica da morte fetal: aproximadamente $30 \%$ (34 casos) de causa desconhecida e entre aque as conhecidas, a hipertensão arterial e o descolamento prematuro de placenta (DPP) apresentaram a incidência maior.

\section{SENTIMENTO EM RELAÇÃO À PERDA}

\section{No Ambiente Hospitalar}

Durante a aplicação do instrumento as autoras tiveram certa dificuldade em tratar sobre o assunto, principalmente pela ausência, na quase totalidade dos casos, de registros nos prontuários a respeito da assistência prestada em relação à perda. Isso obrigou as entrevistadoras a recorrer ao questionamento aos membros da equipe sobre a atitude deles frente à mesma situação; as respostas que foram dadas revelaram em todos as mesmas dificuldades, apenas cada um expressava conforme sua sensibilidade.

- "Evito falar na perda com a paciente, pois considero uma situação delicada" (Enfermeira).

- "Se tiver o coordenador, eu peço para ele dar a notícia, por considerar a pior situaçâo em medicina" (Residente).

- "Não gosto de atender este tipo de paciente" (Auxiliar de Enfermagem).

- "Faço uma pergunta sobre a evolução física para depois falar sobre a morte" (Enfermeira).

- "Vejo se o colo tem condições para indução do parto" (Obstetra).

Constata-se, com efeito, pela expressão destes profissionais, o despreparo dos diferentes membros da equipe para uma ação adequada junto à paciente, tendo em vista a morte fetal. Existe uma preocupação de poupar a mãe. Evita-se falar no assunto. Perpetram-se manobras para fugir desta situação desconfortável, principalmente pelo medo que se sente das emoções fortes (MALDONADO, 1982).

O lidar com a morte continuava sendo, principalmente para as autoras com formação obstétrica, um obstáculo que só foi transposto através do inter-apoio; na medida em que eram relatadas, para as outras colegas, as dificuldades encontradas, surgiram respostas para algumas ansiedades e frutrações, face ao trabalho em andamento.

Algumas palavras facilitaram a aproximação entre as autoras e as māes: "deve ser triste perder o bebê, queres falar, sobre isto? $O$ que tu pensas a este respeito?" As respostas, na maioria dos casos, abriam um caminho para a comunicação: a aproximação oportunizava às mães expressarem seus sentimentos.

Pouco a pouco as barreiras "da morte" foram sendo ultrapassadas, não significando isso a sua aceitação, mas sim, conseguindo passar para as mães objeto da atenção das autoras, elementos que as ajudassem a expressar a morte. A interação obtida com as pacien- 
tes, após esta primeira fase, fez com que as mesmas conseguissem relatar o que estavam sentindo.

A coleta de dados então, passou a ter característi cas diferentes da fase anterior, pois além do roteiro de entrevista ficaram atentos às respostas não verbais (gestos, expressões, entonações e períodos de silêncio).

A primeira vivência que, na entrevista, tentou-se obter das mães foi em relação a maneira como lhes foi transmitida a informação sobre a morte fetal: conforme CADDEN (1980), já na suspeita da morte a equipe adota uma "fala em tons reservados".

O maior impacto constata-se, especialmente, quando, no caso de morte intra-parto, equipe e paciente são surpreendidos, gerando-se com isso, via de regra, uma dificuldade de comunicação entre as partes.

É tão significativa esta constatação, que encontrou-se neste estudo aproximadamente $15 \%$ de mães que não receberam informação sobre a morte $\cdot$ fetal, embora metade destas o suspeitasse, devido às atitudes e expressões da equipe em relação a ela.

"A medida que eu ia sendo examinada começava a desconfiar da morte. Ninguém falou claramente sobre isto, mas senti uma esperança que estivesse viva" (FM a termo em movimentação há 2 dias).

"Ninguém demonstrava preocupação pelo nenê, parecia que só se preocupavam comigo. Eu também não perguntava, mas estava tremendamente preocupada com isto. Quando nasceu pedi para ver e fiquei sabendo que estava morto. Foi muito triste. Ele tinha peso para sobreviver" (FM 31 semanas DPP - cesariana de emergência):

"Muitos me examinavam e ninguém dizia nada. Eles iam e vinham e comecei a suspeitar que alguma coisa não estava certa. Num determinado momento, disseram que eu ia para a tal de ECO. Foi lá, no exame, que o médico disse que o nenê não estava mais vi$v o$ ".

"Eu me cuidei durante toda a gestação indo a todas as consultas, estava tudo bem. Quando começaram as dores do parto, eu e meu marido fomos felizes para o hospital, pois nosso nenê ia chegar. $O$ doutor me examinou e simplesmente disse que infelizmente estava morto. Fiquei chocada, sem conseguir pensar em mais nada, não quis acreditar. Quando ele nasceu tudo se confirmou."

No entanto, estas formas de transmitir a notícia, quer encaminhando para outros profissionais que assumam este fato, quer dizendo diretamente, parece demais superficial, não esclarecendo sobre o que de fato ocorre, não elucidando dúvidas e temores da mãe neste momento. Assim, tomando por base a distinção feita por CROUT (1980) entre as maneiras de comunicar a morte, deve ser of erecida, diretamente à paciente, reconhecendo sua ans iedade e explicando o que está sendo feito, o porquê destes procedimentos, bem como propiciando a livre expressão de seu temor, pois o medo do desconhecido é pior do que a realidade.

A necessidade deste processo fica clara pelas constatações junto às mães, quando da expressão de seus sentimentos pela morte fetal: havia entre elas um sentimento de depressão bastante freqüente (55\%), aumentado por dúvidas e culpas.

"Fiquei muito deprimida e com dúvidas sobre o que estava acontecendo. $O$ doutor falou que eu estava com DPP. O que é isto? Por que aconteceu isto comigo?"
"Para mïn, meu nenê morreu porque não tiraram logo. Não falaram sobre isto comigo. Queria que tivessem falado."

"Me senti como se tivesse uma doença contagiosa; todos fugiam de mim. Quando traziam paciente para a cama ao lado, só cochichavam e levavam a paciente embora, era horrível. Ninguém conversou a este respeito comigo."

"Me senti culpada, tive a impressão que não me cuidei direito, por isso ele morreu. $O$ que eu posso fazer agora?"

A partir dos depoimentos e situações vividas, pode-se considerar que existem dificuldades, tanto da paciente em manifestar seus sentimentos e dúvidas, como da equipe em promover este diálogo. Até que ponto a assistência prestada a estas pacientes, favorecem ou não, suas manifestações vivenciais, incluindo seus temores imaginários?

\section{No Ambiente Domiciliar}

$\mathrm{Na}$ continuidade do acompanhamento a $19 \mathrm{pa}$ cientes em nível domiciliar, onze mostraram-se ainda bastante deprimidas com a situação, sendo que as demais aparentaram estar superando a perda.

Julga-se importante a transcrição dos depoimentos, pois neles se configuram outros aspectos específicos da realidade das mães de feto morto.

Somente na continuidade das entrevistas se captou os sentimentos e reações expressas pelas mães frente ao processo de luto. Aqui, tenta-se apresentar o que foi observado em relação a cada um destes aspectos.

"Eu não queria ficar grávida, mas quando fiquei não queria perder. Na primeira semana que voltei para casa foi muito ruim, começou a melhorar lá na terceira semana. Eu estava mal da pressão e muito deprimida, mas agora estou muito bem, inclusive estou dando de mamar para minha filha de dois anos que eu tinha deixado de amamentar porque o doutor achou melhor parar."

Ao longo da entrevista hospitalar a paciente chorou muito, dizia-se, deprimida com a perda. Mais tarde, já no terceiro mês, apreșentava-se com uma postura tranqüila, alegre e comunicativa, desenvolvia as tarefas do lar e tinha reassumido a tarefa anterior de amamentação que, de certa forma, não havia abandonado apenas por sua decisão individual.

“Eu não queria ficar grávida, porque tinha medo do meu coração, mas até que não foi difícil. Também, eu sabia tudo o que ia acontecer; sabe, a gente quando tem muitos filhos e já tinha morrido dois, não se abala muito. Agora quero ter muita saúde para criar os que eu tenho em casa. Foi triste um pouco quando eu voltei, mas também eu saí de casa com uma 'sangüera' que acho que foi bom voltar caminhando."

$\mathrm{Na}$ entrevista hospitalar, sua expressão foi de pena pela morte da filha, entretanto na continuidade do acompanhamento, em casa, era como se nada tivesse ocorrido, notava-se que estava envolvida com os outros filhos ao seu colo ou agarrados em seus braços.

Estes relatos evidenciam que mesmo entre aque las com gravidez indese jada, o sof rimento faz-se presente na experiência da perda fetal.

$\mathrm{Na}$ segunda visita muitas mães mostraram-se in satisfeitas com relação às pessoas que as cercavam 
deixando transparecer uma tendência à busca do isolamento social após a ocorrência do natimorto. A falta de apoio das pessoas amigas foi também relatada por muitas.

Foram, igualmente, expressas situações de desrespeito ou indif erença por parte de outrem.

"A primeira semana é horrível, ninguém vem dar um apoio, depois vai melhorando um pouco. Chorei muito nos primeiros tempos. Nenhum amigo ou vizinho veio aqui, eles todos fogem da gente. O que me marcou nisso tudo, foi que uma noite, uma funcionária (no hospital), quando eu pedi leite com açúcar para me acalmar, ela me xingou e disse que eu já estava sendo castigada e ainda deveria dar graças, pois assim já tinha pago o que eu merecia. Eu estava me sentindo, só, triste e magoada e ela piorou ainda mais esta situação."

As pessoas, de modo geral, fogem da situação da perda tornando-se importante que a paciente entenda este fato: as pessoas fogem por não saberem o que dizer, por medo de magoar a mãe. Preparação antecipada para a possibilidade da ocorrência deste fato, com explicações das razões da fuga, fará com que as mães não se sintam ainda mais isoladas.

No tipo de atendimento prestado no ambiente hospitalar, parece haver um clima que colabora para levar a puérpera ao sentimento de solidão e de culpa pela morte fetal. COOPER (1979) encontrou entre as preocupações principais expressas pelos pais de feto morto, o comportamento desumanizado da equipe de atendimento. Para STIERMAN (1987) os provedores profissionais de cuidados de saúde lidam com sua ansiedade para à "perda", evitando a situação, reagindo ao paciente de forma hostil e acusadora.

Neste relato, fica claro o quanto a mãe pode ter dificultado o processo de superação da mágoa pela falta de sensibilidade da equipe. É útil que, nas unidades que prestam atendimento a estas pacientes, linhas gerais de conduta e suporte sejam implementadas.

Frente à perda, durante a hospitalização, uma en trevistada concentrou-se no plano místico por ser espiritualista. aceitava bem a perda do bebê, pois a "necessidade de permanência dele na Terra era menor". Apesar da aceitação inicial, este quadro foi revertido. Com o passar do tempo (13 semanas após o parto), ela estava revoltada com seu chefe, indagando sobre os valores de sua vida e questionando a respeito da possi bilidade de ter sido diferente, expressando sentimento de culpa e de fracasso como mãe.

"Eu ainda não estou bem, mas vou superar. No primeiro mês foi difícil, a perda foi muito marcante para mim, cheguei tão perto e não deu certo. Me culpo muito, meus familiares falavam que eu estava trabalhando demais, mas eu não podia fazer repouso devido à mudança lá no meu serviço (mudança de prédio). Estou por perder a chefia (cargo que ocupa), perdi o nenê e quase morri. Pensei que só eu poderia fazer aquele serviço e agora vejo que se eu tivesse morrido, o serviço ia continuar sem mim. Mudei, estou mais voltada para meus familiares e minha filha, acho que vai ser bom perder a chefia. Me dei conta que a familia precisa de mim e no serviço não sou tão insubstituível."

Passado o impacto inicial, as aflições da mãe perduram, ainda por um período de aproximadamente um mês, tempo durante o qual as mães protestam contra a injustiça da morte, buscando suas causas. Podem neste período expressar cólera e hostilidade que segundo STIERMAN (1987) pode ser tanto geral como voltada para algo ou para alguém.

Para O'DONOHUE (1979), “os sentimentos de culpa são universais após a morte”. É inevitável que pais venham a encontrar alguma forma de se culparem mutuamente.

Conversar sobre esta culpa faz com que desenvolvam mecanismos de lidar com a mesma de forma racional.

A mudança no relacionamento e no modo de ser das puérperas, após a perda, foi expressa em metade daquelas com acompanhamento posterior.

"Com os familiares eu não mudei, mas em relação aos colegas de serviço sim. Eu era uma pessoa alegre, agora mudei, estou fechada e mais calada. Sou outra pessoa. A perda é difícil por ser inesperada, se a gente sabe que alguém está doente é mais fácil, mas assim não consigo aceitar. A volta ao serviço foi horrível, tenho colegas que estavam esperando nenê junto comigo $e$ já tem o nenê, ficam mostrando ele para a gente. Não consigo ir a lugar onde tem crianças porque sempre me lembro da minha. Meu outro filho teve várias infecções depois que eu perdi meu nenê, ele adoeceu junto. Meu marido diz que eu só penso nesse assunto, eles não entendem, sentem menos do que a gente."

Nota-se a expressão do sentimento de intensa mágoa e solidão, e a dificuldade de compartilhar com o marido e com os amigos este sentimento.

HARRINGTON (1982) lembra que o pai vê-se em uma situação particularmente vulnerável. Ele evita discutir o assunto por temor de não se controlar. Desta forma, a esposa pode ressentir-se em relação ao marido, acreditando que o mesmo não este ja dando importância ao ocorrido. O relacionamento pode se tornar tenso, gerando sof rimentos para ambos quando, mais do que nunca, marido e mulher têm necessidade um do outro. Por outro lado, a mãe pode levar consideravelmente mais tempo do que o pai para superar a mágoa (BARR \& WIL D, 1984). O importante nesta situação é estimular para que ambos compartilhem os seus sentimentos e que aceitem a ocorrência destes fatos.

É a conspiração do silêncio, dita por LEWIS (1979), que leva a mãe a sofrer desarranjos psicóticos ou o casal a experimentar dificuldades conjugais de relacionamento.

$O$ sentimento intenso de perda faz com que muitas mães passem a descuidar os outros filhos. Acontece, também, a dificuldade no compartilhar com outras mulheres gestantes a vivência da maternidade. Percebe-se ainda, em certas situações, o desagrado pela presença de crianças o que as faz lembrar sua perda. Nesta linha, nota-se a referência anterior, como a que segue:

"A primeira semana foi horrível, mas tinha bastante gente comigo. Até o final do primeiro mês, eu chorava muito. deixei minha outra filha de lado, até que me dei conta que ela existia e que tenho que dar atenção a ela. Minha irmã continuava com sua gravidez e eu não queria que ela conseguisse porque eu perdi o meu. Será que eu sou tão ruim assim para perder o meu? Me dei conta que os planos que eu fiz foram por água abaixo, agora vejo que a gente deve fazer tudo hoje e não deixar para amanhã. Fico horas pensando sozinha, pensando sobre isso."

Os questionamentos aparecem e com eles a culpa, 
vergonha, raiva e depressão todos sentimentos negativos, comuns após a morte do bebê. Mas, se tais sentimentos continuam a ser nutridos, a mãe provavelmente sofrerá distúrbio psicológico significacativo (BARR \& WIL DE, 1984).

"Sinto-me muito só, meu marido não me entende, ele diz que eu só penso neste assunto e tudo é porque eu vi o nenê, mas eu acho que é porque não toquei nele (nenê) e não segurei ele no colo, faltou alguma coisa."

O menor envolvimento do pai com a perda pode fazer com que este não entenda o sof rimento da mãe, podendo levá-lo, em certos casos, a repreender a esposa para que pare de se deprimir (O'DONOHUE, 1979) ou ainda, não entendendo da necessidade de elaboração do processo da perda que ficou incompletò.

Compete ao marido as providências quanto ao processo de registro e enterrro, bem como na vesti . menta do bebê, à mãe cabe unicamente esperar pela alta hospitalar. Freqüentemente as mães relataram que não conversaram sobre o assunto com os maridos e nem eles com as esposas. Talvez todos aqueles preparativos auxiliem o marido no processo de luto enquanto que a mãe - a que sofre mais concretamente a perda - não encontra, muita vez, oportunidade dum diálogo apaziguador com seu companheiro.

Para STIERMAN (1987), na morte perinatal o mais traumático talvez seja o fato da ocorrência inesperada.

A perturbação frente à perda intensifica, em alguns casos, com o passar do tempo, chegando a fobias e dificuldades na vida de relação. As culpas nestes casos encontram terreno fértil.

“A perda assim é difícil por não ter aviso e razão. Estou bastante perturbada, não vou ao banheiro sozinha, nem no portão ou na rua, não consigo ver ninguém com nenê. Quando uma vizinha perdeu o nenê de dois meses chorei muito quando vi o carro fúnebre. Sinto muita angústia, depressão e choro por qualquer motivo. No início eu enxergava a cabeça do nenê por todos os lados: 'é que ele ficou duas horas com a cabeça para fora, o pessoal (equipe) tinha ido almoçar e eu fiquei sozinha sem saber o que fazer. Isso me marcou muito, inclusive agora na relação (sexual) parece que meu marido vai bater na cabeça do nenê."

A imagem incompleta do filho tende a dificultar o processo de luto. A experiência e a pesquisa sugerem que os pais se beneficiem de tanto contato quanto possível com o bebê, a fim de que tenham memória a qual se apegar no período de luto (HARRINGTON, 1982). Assim, caso os pais, num primeiro momento, fiquem indecisos em verem seu fi ho morto, nova oportunidade deve-lhes ser of erecida nas horas subseqüentes quando o medo e temor já podem ter sido superados.

Autores (BARR \& WILDE, 1984; STIERMAN, 1987; CROUCHER, 1982; HARRINGTON, 1982) têm salientado sobre a importância de a mãe ver seu filho morto, para o desenvolvimento do processo de luto. Nas entrevistas, constatou-se que $74 \%$ delas teve esta experiência.

"A gente espera todo o tempo e depois não consegue ver. Não é bom. $O$ primeiro filho nasceu morto $e$ não deixaram ver. Este eu quis ver para me sentir mais conformada. Quando me mostraram, senti uma dor por dentro que eu não sei explicar."

"Eu queria ver para saber como ele era. Pedi pa- ra o médico e ele não deixou ver e disse que eu estava mal e poderia ficar pior."

"Eu pedi para ver e quando me mostraram, era como se ele estivesse dormindo, era perfeito (neste momento do relato a paciente chorou). Para mim foi uma experiência muito marcante que eu não esqueço: ter visto o nenê na hora do parto e antes de ser enterrado. Foi importante porque senão ficaria com a dúvida se ele estava realmente morto."

"No início eu não queria ver o nenê, estava com medo, mas após ter conversado com a enfermeira, decidi vê-lo. Fui até o necrotério e após vê-lo me senti mais tranqüila."

"Eu já sabia da gemelaridade e malformação (anencéfalo) desde o $3^{\circ}$ mês. A princípio nem eu nem meu marido que acompanhou o parto queríamos vê-los. Depois decidimos por fazê-lo e isto nos trouxe um certo alí vio por constatarmos a malformação."

$\mathrm{Na}$ maior parte das entrevistas, verificou-se que rouve iniciativa própria de verem seus recém-nascidos. entre as alegações destas aparecem: "curiosidade"; "ver como era"; "ficar com sua imagem"; "para confirmar a morte". Entre as que permaneceram com dúvidas a respeito de verem ou não o bebê, destacam-se as justificativas: "não foi of erecido": "o médico não deixou" e "não queria ver por medo". A atitude da mãe parece refletir sobre a atitude tomada pela equipe, ou seja, aquelas que já demonstravam o desejo de conhecer seu bebê, foram em grande parte atendi das por esta, embora houvessem excessões. No grupo daquelas mães, que se mostravam ambivalentes a este respeito, poucas receberam atenção da equipe e, como conseqüência, não viram suas crianças.

\section{SUPORTE DE APOIO}

Em relação ao suporte de apoio recebido pelas pacientes; a maioria delas referem tê-lo recebido da equipe de saúde e dos seus familiares: o apoio da equipe de saúde prevaleceu no Centro Obstétrico, enquanto que o apoio of erecido pelos familiares foi em nível de unidade (UIO). Entretanto, cabe salientar que uma quarta parte delas não recebeu nenhum apoio.

"Foi horrível o atendimento no hospital, ficar junto com outra mãe é uma barra, ver a criança viva, escutar o choro aumentou a minha tristeza. A única pessoa que ajudou foi a senhora (pesquisadora): pude dizer aquilo que estava preso dentro de mim."

"A enfermeira e o médico da sala de parto me ajudaram muito, eles disseram que eu 'podia chorar bastante que ninguém sentia como eu'. Depois aqui no andar (UIO), ninguém se importou mais comigo."

"Eu recebi apoio principalmente no Centro Obstétrico (CO), do pessoal de lá. Eu só não queria que me dissessem que sou jovem e posso ter outros filhos. Se tivesse dez (filhos) queria ter este. Fizemos planos para ele. $O$ trabalho de parto foi ruim, mas eu esperava o meu bebê para poder segurá-lo."

"A enfermeira conversou bastante comigo na sala de parto, foi muito bom. Aqui no andar quem tem me ajudado são meus familiares, porque o pessoal daqui não dá a mínima importância e gostaria que soubessem da minha situação. Já veio uma aqui me perguntou: 'cadê teu nenê?' Outra disse: 'trouxe aguinha para teu nenê $e$, deixou a mamadeira do meu lado."

"Recebi bastante apoio do meu médico e de meus 
familiares. O que é importante numa hora desta é alguém para ficar junto, não precisa nem falar."

"Para mim o importante seria meu marido ou familiares, ficarem junto comigo, pois eles sentem como eu."

Como se identifica nos relatos, o apoio dado pela equipe é muito mais em nível de Centro Obstétrico, sendo possivelmente devido ao fato destes profissionais terem tido um envolvimento maior devido à vivência direta muito próxima da ocorrência do evento. Existe para elas a possibilidade bem presente da vivência da morte. Ao contrário do âmbito da equipe de atendimento, na Unidade de Internação Obstétrica detecta-se uma certa negligência em tratar do assunto com a mãe: "uma fuga surgida, em parte, de uma relutância para lidar com o assunto da morte, em um ambiente envolvido com novas vidas" (BOURNE, 1986).

O apoio dos familiares é evidenciado neste momento devido a situação em si própria, da necessidade de tomada de decisão no processo burocrático (registro e funeral) e do enfrentamento social que terão de imediato.

Aqui a família desempenha papel idêntico ao da equipe no nível de Centro Obstétrico: o envolvimento é direto e os "induz" à imediata tomada de decisão. Entretanto, superado este episódio, já no ambiente domiciliar, a família passa a se comportar com menor envolvimento, deixando de falar no assunto, descuidando no apoio à mãe. Se a morte é demasiado terrível e dolorosa para que os próprios membros da equipe evitem falar sobre ela, certamente, não se pode èsperar que a família e os amigos se jam capazes de discutir seus sentimentos: "Os pais aprendem através de nós, que a morte não é para ser mencionada" (O'DONOHUE, 1979).

Quanto ao tipo de apoio que as pacientes referem ter sido importantes, são muito mais do tipo "entender o que estou sentido" e "alguém estar junto", do que tentativas de tranqüilização típica de que "você poderá ter outros filhos" ou negar o problema não tocando no assunto.

O local no hospital onde estas mães devem ficar é problema difícil de ser resolvido. A decisão de onde permanecer após o parto deve ser discutida com a própria mãe. Para algumas, ficar só, seria muito importante; há as que prefeririam a companhia de outras mães e seus bebês.

O'DONOHUE (1979) observa que transferir a mãe para uma unidade de ginecologia pode diminuir a dor que ela sente, mas isso torna-se inapropriado caso se ja interpretado pela mãe como uma punição pelo seu fracasso em dar à luz a um bebê vivo; por outro lado, isso determina que a equipe da maternidade se abstenha de lidar com a paciente.

Não se pode generalizar a assistência porque cada mãe tem sua própria realidade e sentimentos a respeito da perda. Algumas superam com certa facilidade, enquanto que outras precisam de um tempo maior.

\section{CONCLUSÃO}

Constatou-se, nos três hospitais alvo desta pesquisa, uma incidência de natimortalidade de 20,6 em cada mil eventos obstétricos. À primeira vista - 20,6 em mil - pode parecer um dado numérico irrelevante, entretanto, o que se discute, primacialmente, é o mapeamento das questões emocionais e comportamentais que aparecem subjacentes a cada um destes casos enfocando-se tanto a mãe e seus familiares como os profissionais da área de saúde com ela envolvidos no âmbito hospitalar - como uma tentativa para esboçar um conjunto de procedimentos com vistas a minimizar o sof rimento emociond la paciente.

As mães de feto morto, conforme constatado, em sua maioria, encontram-se em estado de angústia, deprimidas, com sentimento de solidão - uma vez que se julgam incompreendidas em seu sof rimento que, ef etivamente, é muito próprio - e, em certos casos, desenvolvendo processo de culpa pela perda. Tal quadro permanece por um intervalo de tempo aproximado de um mês quando, via de regra, todas estas aflições começam a ser superadas.

Por outro lado, pode ser considerado como elemento interveniente naquele estado de crise, o muitas vezes impróprio comportamento de membros da equipe de atendimento, bem como do pai e demais familiares.

Relativamente às informações levadas à mãe sobre a morte fetal, constatou-se que $35 \%$ delas não foram notificadas de imediato ou receberam (ou perceberam) a informação de forma indireta: nota-se aqui a dificuldade dos membros duma equipe de saúde em abordar acerca da consumpção duma expectativa de vida: todos, seres humanos a quem a morte diminui.

Quanto aos sentimentos expressos pelas mães, além dos já notados, caberia aqui salientar: "meu bebê morreu porque não tiraram logo"; "todos fogem de mim"; "me sinto culpada"; "ninguém vem dar apoio"; "meu marido não me entende". Não descabe sublinhar os aspectos que dizem respeito à falta de apoio recebido e à percepção do não envolvimento aparente do pai.

Ademais, salienta-se que muitas das mães disseram que teria sido bom ver o natimorto.

Acerca do apoio reçebido pelas mães, constatou-se ser este um tanto descontínuo. O acompanhamento of erecido pelas equipes dos centros obstétricos parece ter sido o mais adequado. Já em nível de UIO, o atendimento diferenciado parece deixar a dese jar, da mesma forma que, com o correr dos dias, a família, no ambiente domiciliar, passa a descuidar.

Face ao que até aqui procurou-se perpassar, enuncia-se a seguir alguns aspectos a serem tomados como vetores para o delineamento dum modelo de assistência de enfermagem que minimize o sof rimento emocional das mães de feto morto.

1. Parece importante, logo após diagnosticada a morte fetal, que se informe à mãe a respeito, fornecendo-lhe alguns dados acerca da situação. Desta forma, se estará eliminando dúvidas e transmitindo a ela um pouco de segurança para enf rentar à própria situação. A equipe de atendimento dos centros obstétricos deverá estar para tanto preparada de forma que esse acompanhamento inicial - informação da mãe, etc. - se desenvolva com precisão.

2. Julga-se, igualmente necessário, o registro no prontuário das informações dadas à mãe relativas ao acontecimento. Assim procedendo, o mesmo serviria de subsídio para os demais membros da equipe de saúde no lidar junto à paciente, tendo em vista a situação desconfortável em conseqüência da morte fetal.

3. Acredita-se que o procedimento mais adequa- 
do seja, por outro lado, mostrar o natimorto à mãe: ver o feto morto, certamente representará um elemento importante para o processo de aceitação daquela morte. Mesmo quando os pais negam-se a efetivar tal aproximação física, deve-se of erecer uma segunda ou terceira tentativa.

4. Já no âmbito da UIO, é importante que a equipe de atendimento esteja preparada para of erecer uma assistência diferenciada para as mães de feto morto. Conversar com a mãe sobre o evento, escutar e of erecer uma afetuosa dose de realidade parece ser a forma correta de colaborar para a superação do problema.

5. Falar no evento com a mãe parece ser a conduta adequada para todos os que com ela estejam envolvidos. Falar no evento, significa dizer não fugir do assunto de maneira deliberada. Entretanto, trata-se de um falar relativo: no sentido mais de escutar. É importante que a paciente expresse seus sentimentos sobre a profunda angústia que sente. Assim, seguramente, suas condições emocionais, aos poucos, tornam-se melhores. Igualmente, desta forma, se estará eliminando as sensações de abandono e de falta de compreensão presentes nestes momentos. Saber escutar, enfim é fundamental.

6. No ambiente familiar, após a alta hospitalar, também não pode faltar o carinho e a atenção para com a puérpera. Neste sentido deve-se alertar aos familiares sobre as condições especiais de existência em que se encontra a mãe: sua sensibilidade, sua frustração, seus sof rimentos.

"Ninguém pode esquecer a morte de um bebê, na realidade ninguém deseja fazê-lo. Contudo, é necessária a cicatrização e esta ocorre quando lembrar já não é mais doloroso." (L IMMERICK)

\section{REFERÊNCIAS BIBLIOGRÁFICAS}

1 BARR, P. \& WILDE, D. Supportive counselling of parents after a Stillbirth. Australian Family Rhysician. Austrália, 13(8): 621-2, Aug. 1984.

2 BOURNE, S. The psychological effects of Stillbirth on womem and their doctors. Journal of the College of $\mathrm{Ge}$ neral Practiones, 16: 103-12, 1968.

3 CADDEN, Vivian. Crise na família. In: CAPLAN, Geraldo. Princípios de psiquiatria preventiva. Rio de Janeiro, Zahar, 1980. p. 305-15.

4 COOPER, J. End this conspiracy of silence. Nwsing Mirror, Sussex, 149(23):31-3, Dec. 6, 1979.

5 CROUCHER, M. Stillbirth. Nursing Mirror, Sussex, 155(1): XV-XVI, Jul. 7, 1982.
6 CROUT, T. K. Caring for Mother of a Stillborn baby. Nursing, Springhouse, 10(4): 70-3, Apr. 1980.

7 DUARTE, Geraldo et alii. Feto morto 1. Aspectos conceituais e etiopatogênicos. Revista Brasileira de Ginecologia e Obstetrícia, Săo Paulo, 7(3), mai/jun. 1985.

8 FIORI, R. M. et alii. Mortalidade perinatal no Hospital de Clínicas de Porto Alegre. Revista do HCPA, Porto Alegre, $6(1): 1-8$, jun. 1986 .

9 HALSTEAD, Lois. El empleo de la intervención de crisis en la enfermeira obstetrica. Clínica de Enfermeria de Norteamerica, México, 69-76, mar. 1974.

10 HARRINGTON, V. Look, listen and support. Nursing Mirror, Sussex, 154(2): 21-8, Jan. 13, 1982.

11 LAURENTI, L. \& GOTLIEB, M. J. Registro dos eventos vitais. In: _ Estatística de saúde. 2. ed. São Paulo, Pedagógica e universitária, 1987. Cap. 4, p. 39-76.

12 LEWIS, E. Mourning by the family after a Stillbirth on neonatal death. Archives of Disease in Childhood, London, 54: 303-6, 1979.

13 LIMMERICK, L. Countess of counselling parents who have lost and ini..nt. Journal of the Royal College of Physicians of London London, 13:4, 242, 1979.

14 LIPPI, V. G. et alii. Assistência pré-natal. Influência sobre resultados perinatais. Revista Brasileira de Ginecologia e Obstetrí cia, 8(1): 24-8, jan./fev. 1986.

15 MALDONADO, M. T. Temas teóricos: sobre a dialética vida/morte/criação-destruição. In: Maternidade e paternidade. Brasil, Atheneu, 1982. p. 79-100.

16 MONTENEGRO, Carlos A. B. et alii. Indução do parto com feto morto pela administração transcervical de prostaglan PGF 2d). Jornal Brasileiro de Ginecologia, São Paulo, 91(3): 213-6, mai./jun. 1981.

17 O'DONOHUE, N. Facilitating the grief process. Journal of Nurse Midwifery, New York, 24(5): 16-21, Sept./Oct. 1979.

18 ORGANIZAÇĀO MUNDIAL DE SAÚDE. Classificação Internacional de doenças. OMS, 1975. vol. 1, p. 803-9.

19 POWELL, D. "I'm so Miserable" Moodiness. In: Teenagers when to worry and what to do. New York, Doubleday \& Company, 1986. Cap. 9, p. 159-80.

20 STIERMAN, E. D. Emotional Aspects of Perinatal Death. Clinical Obstetrics and Ginecology, New York, 30(2): 352-61, Jun. 1987.

21 VITIELLO, N. Morbiletalidade perinatal. In: FONTES, J.A.S. Perinatologia social. São Paulo, Fundo Editorial Byk-Procienx, 1984. Cap. 10, p. 78-87.

22 WORLD HEALTH ORGANIZATION. Expert commitee on maternity care: First report, a.preliminary survery. Geneva, 1952 (Technical Report Serees, 51). 